\title{
Rehabilitation Intervention for Individuals With Heart Failure and Fatigue to Reduce Fatigue Impact: A Feasibility Study
}

\author{
Young Joo Kim, PhD, OTR/L' ${ }^{1}$, Jennifer C. Radloff, OTD, OTR/L', \\ Patricia A. Crane, PhD, RN ${ }^{3}$, Linda P. Bolin, PhD, MSN, RN, ANP ${ }^{4}$
}

\begin{abstract}
${ }^{1}$ Department of Occupational Therapy, College of Allied Health Sciences, East Carolina University, Greenville, NC; ${ }^{2}$ Department of Occupational Therapy, AdventHealth University, Orlando, FL; ${ }^{3}$ College of Nursing, East Carolina University, Greenville, NC; ${ }^{4}$ Department of Nursing Science, College of Nursing, East Carolina University, Greenville, NC, USA
\end{abstract}

Objective To investigate feasibility of recruitment, tablet use in intervention delivery, and use of self-report outcome measures and to analyze the effect of Energy Conservation plus Problem-Solving Therapy versus Health Education interventions for individuals with heart failure-associated fatigue.

Methods This feasibility study was a block-randomized controlled trial involving 23 adults, blinded to their group assignment, in a rural southern area in the United States. Individuals with heart failure and fatigue received the interventions for 6 weeks through videoconferencing or telephone. Participants were taught to solve their fatiguerelated problems using energy conservation strategies and the process of Problem-Solving Therapy or educated about health-related topics.

Results The recruitment rate was $23 \%$. All participants completed the study participation according to their group assignment, except for one participant in the Energy Conservation plus Problem-Solving Therapy group. Participants primarily used the tablet $(\mathrm{n}=21)$ rather than the phone $(\mathrm{n}=2)$. Self-report errors were noted on Activity Card Sort ( $\mathrm{n}=23)$. Reported fatigue was significantly lower for both the Energy Conservation plus Problem-Solving Therapy ( $\mathrm{p}=0.03, \mathrm{r}=0.49)$ and Health Education $(\mathrm{p}=0.004, \mathrm{r}=0.64)$ groups. The Health Education group reported significantly lower fatigue impact $(\mathrm{p}=0.019, \mathrm{r}=0.48)$. Participation was significantly different in low-physical demand leisure activities $(\mathrm{p}=0.008 ; \mathrm{r}=0.55$ ) favoring the Energy Conservation plus Problem-Solving Therapy group.

Conclusion The recruitment and delivery of the interventions were feasible. Activity Card Sort may not be appropriate for this study population due to recall bias. The interventions warrant future research to reduce fatigue and decrease participation in sedentary activities (Clinical Trial Registration number: NCT03820674).

Keywords Heart failure, Fatigue, Activity participation, Rehabilitation, Occupational therapy

Received June 12, 2019; Accepted August 7, 2019

Corresponding author: Young Joo Kim

Department of Occupational Therapy, College of Allied Health Sciences, East Carolina University, Health Sciences Building 3305,600 Moye Blvd, Greenville, NC 27834, USA. Tel: +1-252-744-6191, Fax: +1-252-744-6198, E-mail: kimyo15@ecu.edu

ORCID: Young Joo Kim (http://orcid.org/0000-0002-6258-7463); Jennifer C. Radloff (http://orcid.org/0000-0002-0275-6149); Patricia A. Crane (http:// orcid.org/0000-0002-4710-3133); Linda P. Bolin (http://orcid.org/0000-0002-2889-3459).

(a) This is an open-access article distributed under the terms of the Creative Commons Attribution Non-Commercial License (http://creativecommons.org/ licenses/by-nc/4.0) which permits unrestricted noncommercial use, distribution, and reproduction in any medium, provided the original work is properly cited. Copyright $\odot 2019$ by Korean Academy of Rehabilitation Medicine 


\section{INTRODUCTION}

Heart failure (HF) is defined as a clinical syndrome caused by cardiac disorders with impairments in ventricle filling or ejection of blood [1]. Due to the advancements in management of cardiovascular diseases, survival rate has improved over the years, resulting in an increased number of older adults with HF in the community. In addition, the incidence of HF doubles with each decade after the age of 65 years [2], where HF with preserved ejection fraction more often observed in older adults than reduced ejection fraction. Fatigue is one of the 'cardinal symptoms' in individuals with HF followed by dyspnea and chest pain [3]. Individuals with HF report higher levels of fatigue and have 8 times greater risk of having fatigue symptoms than the healthy population [4]. The negative effects of fatigue in people with HF include depression, lower physical health, emotional health, and quality of life [5]. Thus, fatigue negatively affects the ability to perform instrumental activities of daily living, such as food preparation, house cleaning, and recreational and social activities $[6,7]$. Due to the increasing number of people with 'chronic' HF, providing care is becoming more complex [8]. Interventions to mitigate or decrease fatigue in those with HF would improve health, performance in activities of daily living, and thus, positively affect quality of life.

There is no unified definition or terminology for fatigue in people with cardiac conditions. A unified taxonomy devised for fatigue in people with neurological conditions [9] can be carefully applied to people with cardiac conditions. Under this unified taxonomy, fatigue is categorized into two distinct domains: performance fatigability and perceptions of fatigue. Performance fatigability is defined as the "rate of change in a performance criterion relative to a reference value over a given time of task performance" [9]. Fatigability is similar to behavioral fatigue, which is the inability to continue physical and/or mental activity over time and can be measured objectively [8]. Some measures of fatigability are changes in torque, power, or speed after exercise for motor ability, and changes in reaction time or accuracy after cognitively challenging tasks for cognitive ability [9]. In contrast to performance fatigability, perceptions of fatigue are defined as "subjective sensations of weariness, increasing sense of effort, mismatch between effort expended and actual perfor- mance, or exhaustion" [9]. Similarly, subjective physical fatigue refers to the feeling of tiredness that a person experiences upon physically completing activities, whereas subjective mental fatigue refers to the feeling of tiredness that a person experiences when paying attention to tasks [10]. Perceptions of fatigue can be measured using selfreport assessments evaluating different aspects of subjective fatigue, such as state, severity, and reports of impact on function $[9,11]$.

Despite the various negative effects of fatigue in people with HF, there is a limited number of non-pharmacological interventions and evidence for fatigue management. Exercise training was shown to decrease the symptoms of fatigue, although there have been inconsistent results [12-14]. An Internet-based fatigue management intervention to reduce fatigue in individuals with HF did not demonstrate a significant change in fatigue in the intervention group compared to that in the control group [15]. In non-HF populations, energy conservation (EC) has demonstrated effectiveness in reducing fatigue. Although the methods of education were different, EC has been shown to be effective in reducing fatigue impact in people with multiple sclerosis [16]. In a sample of cardiac arrest survivors with chronic fatigue, researchers have shown EC strategies delivered through the framework of Problem-Solving Therapy (PST) as an effective intervention to reduce fatigue [17]. No studies were found using EC and PST to manage fatigue in individuals with HF. Therefore, the primary aims of this feasibility study were to determine: (1) the feasibility of recruiting and retaining participants in rural Eastern North Carolina (in terms of recruitment rate), (2) the feasibility of using a tablet computer for intervention delivery (in terms of familiarity and Internet access), and (3) the appropriate outcome measures for fatigue and activity participation. We also reported the outcomes of this feasibility study on the effectiveness of an Energy Conservation plus ProblemSolving Therapy (EC+PST) compared to Health Education alone in reducing the fatigue level and impact, and improving the level of participation in instrumental, leisure, and social activities for people with HF-associated fatigue. 


\section{MATERIALS AND METHODS}

\section{Study design}

This study was a single-center, parallel-group, block and equally randomized controlled trial. Pretest and posttest were completed 7-10 days prior to the first intervention session and 7-10 days following the last intervention session, respectively.

\section{Participants}

A total of 23 adults with HF diagnosis and self-reported fatigue participated in this study, with 11 adults assigned to the EC+PST group and 12 adults assigned to the Health Education group. Inclusion criteria included (1) a minimum of 6 months since being diagnosed with any type of HF and 3 months post-hospitalization, (2) reporting of moderate to severe fatigue by scoring $\geq 4$ according to the Fatigue Severity Scale [18], (3) living in the community, (4) having access to the Internet or telephone at the place of residence, (5) having functional English fluency, and (6) having functional vision to operate the tablet computer. Individuals were excluded if they had a score of $\geq 9$ in the Short Blessed Test [19] indicating cognitive impairment, or were classified as having New York Heart Association (NYHA) Functional Classification level IV on their medical record. The diagnosis of HF was confirmed through the past medical history of HF in the medical record, the presence of NYHA Functional Classification in the medical record, and/or confirmation by the participants' healthcare provider.

\section{Demographic and medical information}

Demographic and medical information were collected using the two-page form created for this study. The demographic form included variables of age, ethnicity, sex, highest education completed, and living status. In addition to the medical information related to HF, such as years since diagnosis with HF and ejection fraction, information on the history of risk factors [13] and history of major diagnoses was collected. Lastly, the Charlson Comorbidity Index was included in the medical information [20].

\section{Descriptive measures}

\section{Center for Epidemiologic Studies Depression Scale}

The Center for Epidemiologic Studies Depression Scale measures the level of depressive symptomatology over the past 7 days using 20 items. Scores range from 0 to 60 , and a score of 16 or greater indicates depressive symptoms. It has been shown to be reliable and valid [21].

\section{Keitel Functional Test}

Keitel Functional Test measures 24 movement patterns in terms of range of motion and muscle activity in different positions, such as bending fingers, prayer position, external rotation of hip joints in standing, walking $30 \mathrm{~m}$, and walking up and down the stairs. Scores range from 0 to 100 , and the higher score indicates more restriction in movement. The Keitel Functional Test has been shown to have good reliability and acceptable concurrent validity [22].

\section{Media and Technology Usage and Attitudes Scale}

Media and Technology Usage and Attitudes Scale measures an individual's media and technology usage and attitudes toward media and technology, but only the usage subscales of smartphone, Internet searching, e-mailing, media sharing, text messaging, video gaming, phone calling, and television viewing were measured in the current study using 31 items. Scores range from 31 to 310 , and the higher score indicates higher usage of media and technology. This scale showed acceptable to excellent reliabilities and small to large concurrent validities in all subscales [23].

\section{Feasibility outcome measures}

To assess the feasibility of recruiting and retaining participants, the number of people referred, the number of people screened, the number of eligible people, and the number of people who completed the study participation were collected throughout the study. To assess the feasibility of using a tablet computer for intervention delivery, the number of people who did not have internet access at home among those screened and the number of people who had access to the internet but were not able to receive the intervention via tablet due to unfamiliarity with the tablet were recorded. Lastly, to determine appropriate outcome measures, information on ceiling and flooring effects, and problems identified during the administration of intervention outcome measures, was collected. 
Intervention outcome measures

\section{PROMIS Fatigue $8 a$}

Patient-Reported Outcomes Measurement Information System Short Form 8a - Fatigue (PROMIS Fatigue 8a) was the primary outcome measure among the intervention outcome measures. PROMIS Fatigue 8a measures selfreported fatigue over the past 7 days in terms of intensity and frequency using 8 items. It generates a standardized score with a mean of 50 and a standard deviation of 10 . A score of 50 represents the average of the general population in the United States. The higher score indicates worse fatigue. It showed excellent reliability and good precision and was validated in people with $\mathrm{HF}[24,25]$.

\section{Fatigue Impact Scale}

The Fatigue Impact Scale measures the impact of fatigue over the past month in terms of functional limitations from fatigue using 40 items in three subscales. Total score ranges from 0 to 160 , and a higher score indicates more functional limitations from fatigue. It has shown robust psychometric properties in test-retest reliability, convergent validity, and external validity in individuals with multiple sclerosis and other chronic conditions, but not in people with HF [26]. However, these chronic conditions, including multiple sclerosis and HF, share common characteristics of unusual fatigue that do not improve with rest.

\section{Activity Card Sort Form B}

Activity Card Sort measures the currently retained participation level compared to 'prior to illness' using 89 photographs of activities categorized into instrumental activities, low-physical demand leisure activities, highphysical demand leisure activities, and social activities. In Form B, an interviewee classifies 89 photographs into 'not done prior to current illness,' 'continue to do during illness,' 'do less since illness,' 'given up due to illness', or 'new activity since illness' based on their current participation status. Scores range from $0 \%-100 \%$, and a higher score indicates higher retention of participation level. It has demonstrated good internal consistency, test-retest reliability, and content and construct validity [27].

\section{Procedures}

After approval from University and Medical Center Institutional Review Board of East Carolina University
(No. UMCIRB 16-000078), clinicians in inpatient and outpatient units of level-1 trauma medical center and the Veterans Affairs Health Care Center, such as cardiac intensive care units, HF clinics, and cardiopulmonary rehabilitation centers, referred potential participants to the study. We then administered screening via telephone using the eligibility criteria. Those fitting the study criteria provided written informed consent and were randomly assigned to either the EC+PST group or the Health Education group using sealed envelopes, blocked by six (three EC+PST and three Health Education). A non-study person selected the sealed envelope, and the principal investigator assigned participants to groups according to the selected envelope. Participants were blinded to the group assignment.

All data collection occurred in the participant's home. The first data collection (pretest) included completing the demographic form, and administering descriptive and intervention outcome measures. In addition, we oriented participants to using a tablet computer and WebEx application using a handout with directions and color pictures. Participants practiced the use of WebEx application on a tablet computer until they were successful. During this visit, participants also received the Participant Workbook that was used throughout the intervention sessions. Medical information was collected primarily from participants' medical records and from the participants themselves, if there was any missing information. Participants received the intervention within 7-10 days following the pretest via either Cisco WebEx using Amazon Kindle Fire 7 tablet (5th generation) or by telephone. Cisco WebEx is a secure, HIPAA-compliant, video and audioconferencing meeting system and requires paidsubscription for a meeting host but not for the attendees. Cisco WebEx provides multiple system platform options including Windows, Mac, iOS, and Android [28]. The investigators' institution had an institutional subscription to Cisco WebEx during the study period, and participants received the link to the video-conferencing sessions by email prior to the scheduled sessions. Amazon Kindle Fire 7 tablet, 5th generation, is an inexpensive, Androidbased tablet computer and has a 7-inch display, $13 \mathrm{GHz}$ quadcore processor, and 8 GB storage capacity [29]. Participants kept the Amazon Kindle Fire 7 tablet as an incentive upon completion of study participation.

Once participants completed the intervention sessions, 
investigators again visited participants' homes to administer intervention outcome measures for posttest within 7-10 days following the last intervention session. Assessors and interventionists were not blinded to the study design or group assignment, although all intervention outcome measures were self-reported, reducing potential bias from the assessors. The principal investigator has expertise in EC+PST intervention and the assessments used in this study, and trained the research assistants in the administration of the assessments and interventions prior to the sessions. The research assistants also observed the assessment and intervention sessions at least once prior to their administration. The principal investigator was present in all assessment sessions and observed $10 \%$ of the intervention sessions to verify intervention fidelity.

\section{EC+PST intervention and Health Education intervention}

EC+PST intervention sessions occurred twice a week for 30-45 minutes for up to 12 sessions (a total of 6 weeks). EC strategies are designed to assist individuals in completing tasks without expanding more energy [30], and these strategies may include principles, such as 'taking rest periods, controlling the pace of work, and arranging supplies within normal reach' [17]. To help participants apply the EC strategies to their own fatigue-related problems, EC+PST intervention incorporated the process of PST. PST is a psychosocial intervention that has been used with various mental health conditions, including depression, anxiety, cancer, heart disease, and traumatic brain injury [31]. Of the two components of PST, including problem orientation and problem-solving skills, the process of problem-solving relevant to EC+PST intervention was adopted. Specifically, problem-solving skills of PST include seven steps: (1) identifying problems, (2) establishing goals, (3) generating solutions, (4) evaluating solutions, (5) developing an action plan, (6) implementing the action plan, and (7) assessing the outcome [31]. During Session 1, a participant and an interventionist reviewed the rules of attendance to the session, HF symptoms, and impact of HF fatigue. During Session 2, EC strategies and EC+PST intervention steps were reviewed using example worksheets. Then, by the end of Session 4, the participant and the interventionist together identified two to four fatigue-related problems, and details of those problems, through discussion. During the subsequent one to two sessions, the participant and the intervention- ist established a goal and created potential solutions and an action plan for the first fatigue-related problem. The participant implemented the action plan on their own between sessions and reviewed their implementation with the interventionist during the very next session. Later steps (Sessions 3-5) were repeated until the participant addressed up to four fatigue-related problems or reached 12 intervention sessions. An EC+PST Participant Workbook with worksheets was used throughout the sessions, and participants kept the Workbook upon the completion of their study participation.

Health Education intervention sessions occurred once a week for 30-45 minutes for up to six sessions. Participants learned about HF symptoms, HF fatigue, stress and mood, EC strategies, exercise, and healthy diet using a Health Education Participant Workbook. Interventionists were not allowed to discuss how the information could be applied to the specific participant's problems to differentiate the Health Education intervention from the EC+PST intervention (Table 1).

\section{Statistical analyses}

Descriptive statistics were used to describe the participants, their satisfaction in the interventions, and their level of understanding of the workbooks. For intervention outcome measures, due to the violation of normal distribution, the Wilcoxon signed-rank test was used for within group comparisons, and the Mann-Whitney U test was used for between group comparisons of changes. Both total and subscale scores of intervention outcome measures, when available, were analyzed. For all statistical analyses, an alpha level of 0.05 was used, except for subscale analyses. According to the Bonferroni correction, we used conservative alpha levels of 0.017 for analyses of three Fatigue Impact Scale subscales and 0.0125 for analyses of four Activity Card Sort subscales. Effect sizes (r) were calculated to document the degrees of change between pretest and posttest within each group and differences in those changes between groups. The formula $r=\frac{Z}{\sqrt{n}}$, where $\mathrm{Z}$ was obtained from the Wilcoxon signed-rank test for within group comparisons, and the Mann-Whitney U test for between group comparisons was used to calculate the effect sizes. Effect size $r$ values between 0 and 0.09 indicate a negligible effect, values between 0.10 and 0.23 indicate a small effect, values be- 
Table 1. Summary of the study interventions by session

\begin{tabular}{|c|c|c|}
\hline & EC+PST intervention & Health Education intervention \\
\hline Week 1 & $\begin{array}{l}\text { Session } 1 \\
\text { - Review of the session rules, heart failure symp- } \\
\text { toms, impact of heart failure fatigue, and budget- } \\
\text { ing and banking energy. } \\
\text { Session } 2 \\
\text { - Review of EC+PST intervention steps using ex- } \\
\text { ample sheets. }\end{array}$ & $\begin{array}{l}\text { Session } 1 \\
\text { - Review of the session rules and education on } \\
\text { heart failure and fatigue in heart failure. }\end{array}$ \\
\hline Week 2 & $\begin{array}{l}\text { Sessions } 3 \text { and } 4 \\
\text { - Identification of four fatigue-related problems } \\
\text { and details of those problems. }\end{array}$ & $\begin{array}{l}\text { Session } 2 \\
\text { - Education on impact of heart failure fatigue and } \\
\text { stress and mood including relaxation techniques. }\end{array}$ \\
\hline Week 3 & $\begin{array}{l}\text { Sessions } 5 \text { and } 6 \\
\text { - Goal setting and creation of solutions and an ac- } \\
\text { tion plan for Problem } 1 \text {. } \\
\text { - Participants implemented the action plan be- } \\
\text { tween Session } 6 \text { and Session } 7 \text {. }\end{array}$ & $\begin{array}{l}\text { Session } 3 \\
\text { - Education on energy conservation, such as bud- } \\
\text { geting and banking energy, how to modify activi- } \\
\text { ties and communicate with others about fatigue, } \\
\text { and importance of rest and sleep. }\end{array}$ \\
\hline Week 4 & $\begin{array}{l}\text { Sessions } 7 \text { and } 8 \\
\text { - Review of the implementation of the action plan } \\
\text { for Problem } 1 . \\
\text { - Goal setting and creation of solutions and an ac- } \\
\text { tion plan for Problem } 2 \text {. } \\
\text { - Participants implemented the action plan be- } \\
\text { tween Session } 8 \text { and Session } 9 \text {. }\end{array}$ & $\begin{array}{l}\text { Session } 4 \\
\text { - Education on energy conservation, such as bud- } \\
\text { geting and banking energy, how to modify activi- } \\
\text { ties and communicate with others about fatigue, } \\
\text { and importance of rest and sleep (continued). }\end{array}$ \\
\hline Week 5 & $\begin{array}{l}\text { Sessions } 9 \text { and } 10 \\
\text { - Review of the implementation of the action plan } \\
\text { for Problem } 1 \text {. } \\
\text { - Goal setting and creation of solutions and an ac- } \\
\text { tion plan for Problem } 3 \text {. } \\
\text { - Participants implemented the action plan be- } \\
\text { tween Session } 11 \text { and Session } 12 \text {. }\end{array}$ & $\begin{array}{l}\text { Session } 5 \\
\text { - Education on regular exercise, such as benefits, } \\
\text { warning signs of heart problems, and exercise } \\
\text { guidelines. }\end{array}$ \\
\hline Week 6 & $\begin{array}{l}\text { Sessions } 11 \text { and } 12 \\
\text { - Review of the implementation of the action plan } \\
\text { for Problem } 1 \text {. } \\
\text { - Goal setting and creation of solutions and an ac- } \\
\text { tion plan for Problem } 4 \text {. } \\
\text { - Participants implemented the action plan after } \\
\text { Session } 12 \text {. }\end{array}$ & $\begin{array}{l}\text { Session } 6 \\
\text { - Education on healthy diet, such as how to limit } \\
\text { fluid and salt intake. }\end{array}$ \\
\hline
\end{tabular}

EC+PST, Energy Conservation plus Problem-Solving Therapy.

tween 0.24 and 0.36 indicate a medium effect, values between 0.37 and 0.70 indicate a large effect, and values 0.71 or greater indicate a very large effect [32].

\section{RESULTS}

Mean ages were 66.9 years $(\mathrm{SD}=15.1)$ for the $\mathrm{EC}+\mathrm{PST}$ group and 60.2 years $(\mathrm{SD}=15.9)$ for the Health Education group. The majority of participants were male (69.6\%), had high school or higher education (91.3\%), and lived with someone else (73.9\%). None was screened positive for cognitive impairment at the beginning of the study. The mean of Center for Epidemiologic Studies Depression Scale for the EC+PST group was below the cutoff for depressive symptoms, whereas the Health Education group was above the cutoff $(\geq 16)$ (Table 2). On average, the EC+PST and Health Education groups had been diagnosed with HF for 6.7 years $(\mathrm{SD}=7.2)$ and 8.8 years $(\mathrm{SD}=4.7)$, respectively. Approximately half of the participants were obese $(n=11,47.8 \%)$, and the majority were in 
Table 2. Demographics of participants and results of the descriptive measures

\begin{tabular}{|c|c|c|c|}
\hline & $\begin{array}{c}\text { EC+PST } \\
(n=11)\end{array}$ & $\begin{array}{c}\mathrm{HE} \\
(\mathrm{n}=12)\end{array}$ & p-value \\
\hline Age (yr) & $66.9 \pm 15.1$ & $60.2 \pm 15.9$ & 0.310 \\
\hline Race, White & $8(72.7)$ & $6(50.0)$ & \\
\hline Sex, male & $7(63.6)$ & $9(75.0)$ & \\
\hline$\geq$ High school & $11(100.0)$ & $10(83.0)$ & \\
\hline Lives alone & $3(27.3)$ & $3(25.0)$ & \\
\hline Fatigue Severity Scale & $5.71 \pm 0.58$ & $5.96 \pm 0.79$ & \\
\hline Short Blessed Test & $1.00 \pm 1.18$ & $1.92 \pm 2.47$ & \\
\hline CES-D & $15.55 \pm 10.46$ & $19.75 \pm 8.41$ & 0.298 \\
\hline KFT & $20.64 \pm 10.04$ & $22.67 \pm 14.56$ & 0.704 \\
\hline MTUAS & $113.27 \pm 60.95$ & $106.67 \pm 63.06$ & 0.801 \\
\hline
\end{tabular}

Values are presented as mean \pm standard deviation or frequency (\%).

EC+PST, Energy Conservation plus Problem-Solving Therapy; HE, Health Education; CES-D, Center for Epidemiological Studies Depression scale; KFT, Keitel Functional Test; MTUAS, Media and Technology Usage and Attitudes Scale.

NYHA Classification II or III (Table 3). The EC+PST and Health Education groups were not significantly different in age, months since last admission to the hospital, ejection fraction, body mass index, Charlson Comorbidity Index, or descriptive measures ( $p>0.05$ ).

\section{Primary aims}

The study recruitment began in July of 2016, and we received the last referral in February of 2018. A total of 99 referrals during the 20 -month period resulted in a recruitment rate of $23 \%$. Of the 99 referrals, $49.5 \%(n=49)$ declined to participate, $32.3 \%(n=32)$ were determined eligible, and 23 participants $(23.2 \%)$ completed the pretest, all intervention sessions, and posttest. One participant received the pretest and all intervention sessions but dropped out of the study due to an urgent medical issue unrelated to his study participation (Fig. 1).

One individual at the screening process reported no internet access at home or enough minutes on his cell phone for sessions. Two participants received the interventions over the telephone due to a lack of Internet access at home or an Internet speed issue. Otherwise, all other individuals screened reported that they had access to either the Internet or telephone at home. All participants were able to follow the directions on the handout for a tablet computer and WebEx app, and no participant dropped out of the study due to their inability to use a tablet computer or WebEx app. All participants who received the intervention over a tablet computer and WebEx experienced technical issues during at least one session, although the issues were resolved through problem-solving with an interventionist via telephone. All participants completed intervention outcome measures within 20-30 minutes without difficulty, except for Activity Card Sort. All participants classified 'not done prior to illness' activities differently at pretest and posttest possibly due to recall bias as these activities may have occurred 6 years earlier. Therefore, any activities participants reported as 'not done prior to illness' either at pretest or posttest were considered as 'not done prior to illness.'

\section{Secondary aims}

Both the EC+PST and Health Education groups reported significantly lower fatigue at posttest than pretest $(\mathrm{p}=0.03$ and $\mathrm{p}=0.004$, respectively) with large effect sizes ( $\mathrm{r}=0.49$ and $\mathrm{r}=0.64$, respectively) according to PROMIS Fatigue $8 \mathrm{a}$, and the improvements on the PROMIS Fatigue 8a were not significantly different between groups $(\mathrm{p}=0.43)$. The Health Education group reported significantly lower fatigue impact at posttest than pretest $(\mathrm{p}=0.019)$ with a large effect size $(r=0.48)$ without significant differences between groups on the Fatigue Impact Scale $(p=0.06)$. There was a significant difference in Activity Card Sort low-physical demand leisure activities between the $\mathrm{EC}+\mathrm{PST}$ and Health Education groups $(\mathrm{p}=0.008)$ with a large effect size $(\mathrm{r}=0.55)$ with those in the EC+PST group reporting more decrease in participation (Table 4).

\section{DISCUSSION}

Recruiting and retaining participants from a rural southern area in the United States was feasible; however, recruitment was more challenging than retention. We received a total of 99 referrals from eight different sources during the 20 months. Although the referral rate was not consistent, on average, we received approximately five referrals monthly. Higher referral rates are needed to recruit an adequate sample to strengthen internal validity. This may be achieved through recruiting at multiple 
Table 3. Medical information of participants

\begin{tabular}{|c|c|c|c|}
\hline & EC+PST $(n=11)$ & HE $(n=12)$ & p-value \\
\hline Years since diagnosed with HF & $6.7 \pm 7.2$ & $8.8 \pm 4.7$ & \\
\hline Months since last hospital admission & $16.36 \pm 16.1$ & $14.33 \pm 18.5$ & \\
\hline BMI, $\geq 30 \mathrm{~kg} / \mathrm{m}^{2}$ & $5(45.5)$ & $6(50.0)$ & 0.944 \\
\hline Ischemic cardiomyopathy & $6(54.5)$ & $8(66.7)$ & \\
\hline Presence of pacemaker or defibrillator & $4(36.4)$ & $5(41.7)$ & \\
\hline Ejection fraction (\%) & $50.23 \pm 14.9$ & $39.29 \pm 13.4$ & 0.077 \\
\hline Estimated right ventricular systolic pressure ${ }^{\mathrm{a})}(\mathrm{mmHg})$ & $73.0 \pm 40.2$ & $35.6 \pm 7.2$ & \\
\hline \multicolumn{4}{|l|}{ NYHA class } \\
\hline I & $1(9.1)$ & $1(8.3)$ & \\
\hline II & $6(54.5)$ & $6(50.0)$ & \\
\hline III & $4(36.4)$ & $5(41.7)$ & \\
\hline \multicolumn{4}{|l|}{ Risk factors history } \\
\hline Smoking & $7(63.6)$ & $6(50.0)$ & \\
\hline Alcohol abuse & 0 & $5(41.7)$ & \\
\hline Cocaine & 0 & 0 & \\
\hline Arthritis & $3(27.3)$ & $8(66.7)$ & \\
\hline Intravenous drug use & 0 & 0 & \\
\hline Hypertension ( $\geq 140 / 90 \mathrm{mmHg}$ ) & $11(100.0)$ & $10(83.3)$ & \\
\hline Diabetes & $6(54.5)$ & $7(58.3)$ & \\
\hline Myocardial infarction & $6(54.5)$ & $6(50.0)$ & \\
\hline Angina & $3(27.3)$ & $1(8.3)$ & \\
\hline Left ventricular hypertrophy & $3(27.3)$ & $1(8.3)$ & \\
\hline Valvular heart disease & $2(18.2)$ & $2(16.7)$ & \\
\hline \multicolumn{4}{|l|}{ History of major diagnoses } \\
\hline Cerebrovascular accident & $3(27.3)$ & $2(16.7)$ & \\
\hline Peripheral vascular disease or bypass & $1(9.1)$ & $4(33.3)$ & \\
\hline Chronic obstructive pulmonary disease & $2(18.2)$ & $2(16.7)$ & \\
\hline Dementia & 0 & 0 & \\
\hline Malignancy & $3(27.3)$ & 0 & \\
\hline Traumatic brain injury & $1(9.1)$ & 0 & \\
\hline Multiple sclerosis & 0 & 0 & \\
\hline Coronary artery disease & $7(63.6)$ & $8(66.7)$ & \\
\hline Severe valvular heart disease & $1(9.1)$ & 0 & \\
\hline Hypothyroidism & $3(27.3)$ & $1(8.3)$ & \\
\hline Depression & $4(36.4)$ & $3(25.0)$ & \\
\hline Anxiety & $2(18.2)$ & $1(8.3)$ & \\
\hline Charlson Comorbidity Index & $6.2 \pm 2.5$ & $5.3 \pm 2.7$ & 0.45 \\
\hline
\end{tabular}

Values are presented as mean \pm standard deviation or frequency (\%).

EC+PST, Energy Conservation plus Problem-Solving Therapy; HE, Health Education; HF, heart failure; NYHA, New York Heart Association functional classification.

${ }^{\text {a) }} \mathrm{n}=4$. 


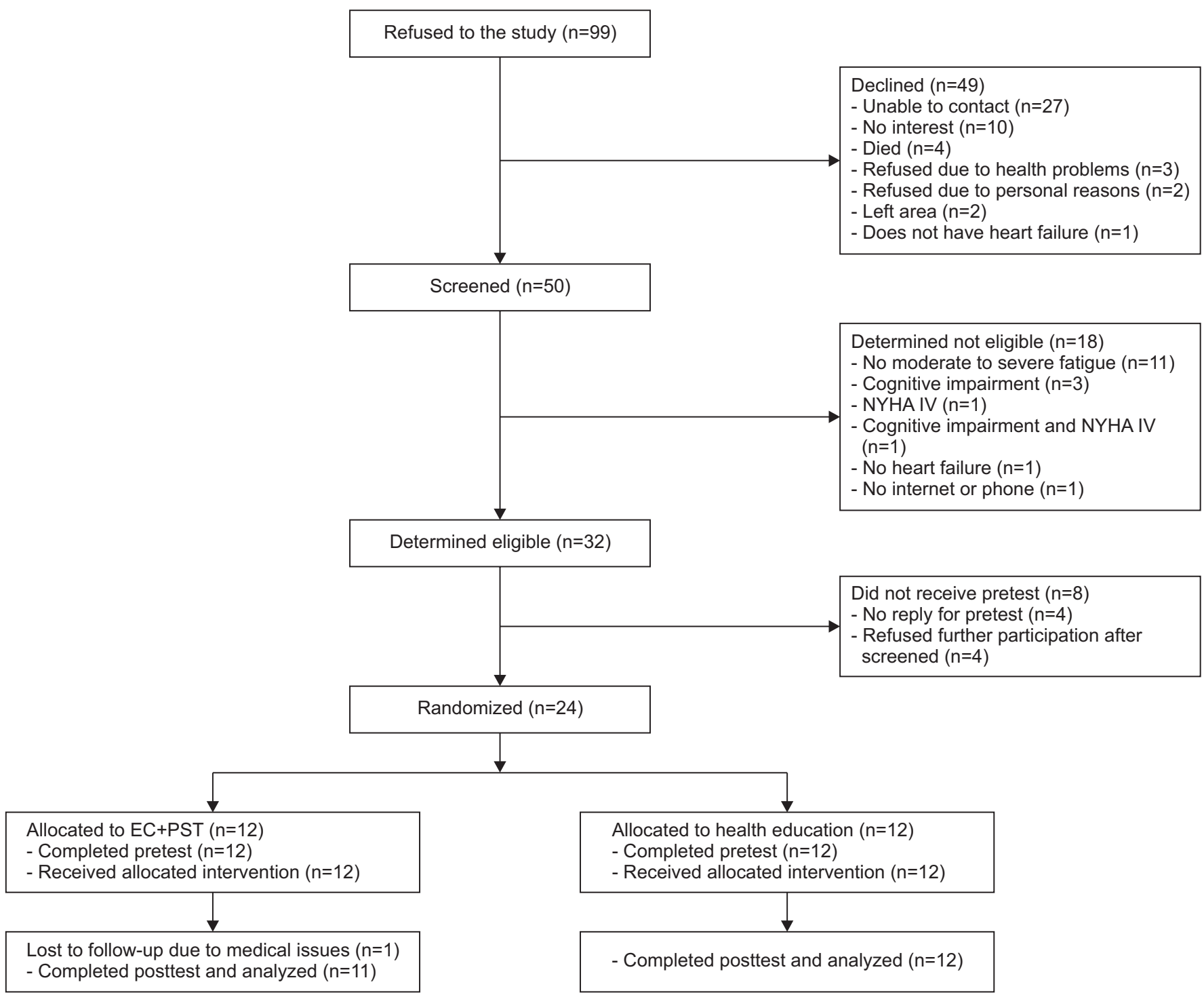

Fig. 1. Flow of screening process and study completion. NYHA, New York Heart Association functional classification; EC+PST, Energy Conservation plus Problem-Solving Therapy.

hospitals [33], although this will require collaborators who are geographically close to those hospitals due to inperson data collection. Among the 99 individuals initially referred to the study, we were not able to reach 27 of them due to non-working numbers and unreturned calls. One potential solution to this is obtaining multiple contact numbers.

Using a tablet computer and WebEx app for intervention delivery was feasible. Only two individuals did not have Internet access: one at screening and one during data collection. Although we experienced technical problems for almost all participants, each was resolvable. The number of technical problems may be decreased by adopting more reliable tablet computers or a simpler operating system, such as iPad and iOS, which give restrictive control to users and allow smooth connection to WebEx. Otherwise, participants were able to follow directions on the handout guiding control of the tablet computer and WebEx app for successful session completion. Distance-delivery methods, including Internet-based and telephone-based interventions, have been used to reach rural settings in multiple studies and have shown to be valuable because of the limited access to healthcare that rural populations often experience [34,35]. Based on our findings of the wide availability of Internet access or home telephone in Eastern North Carolina in the United 


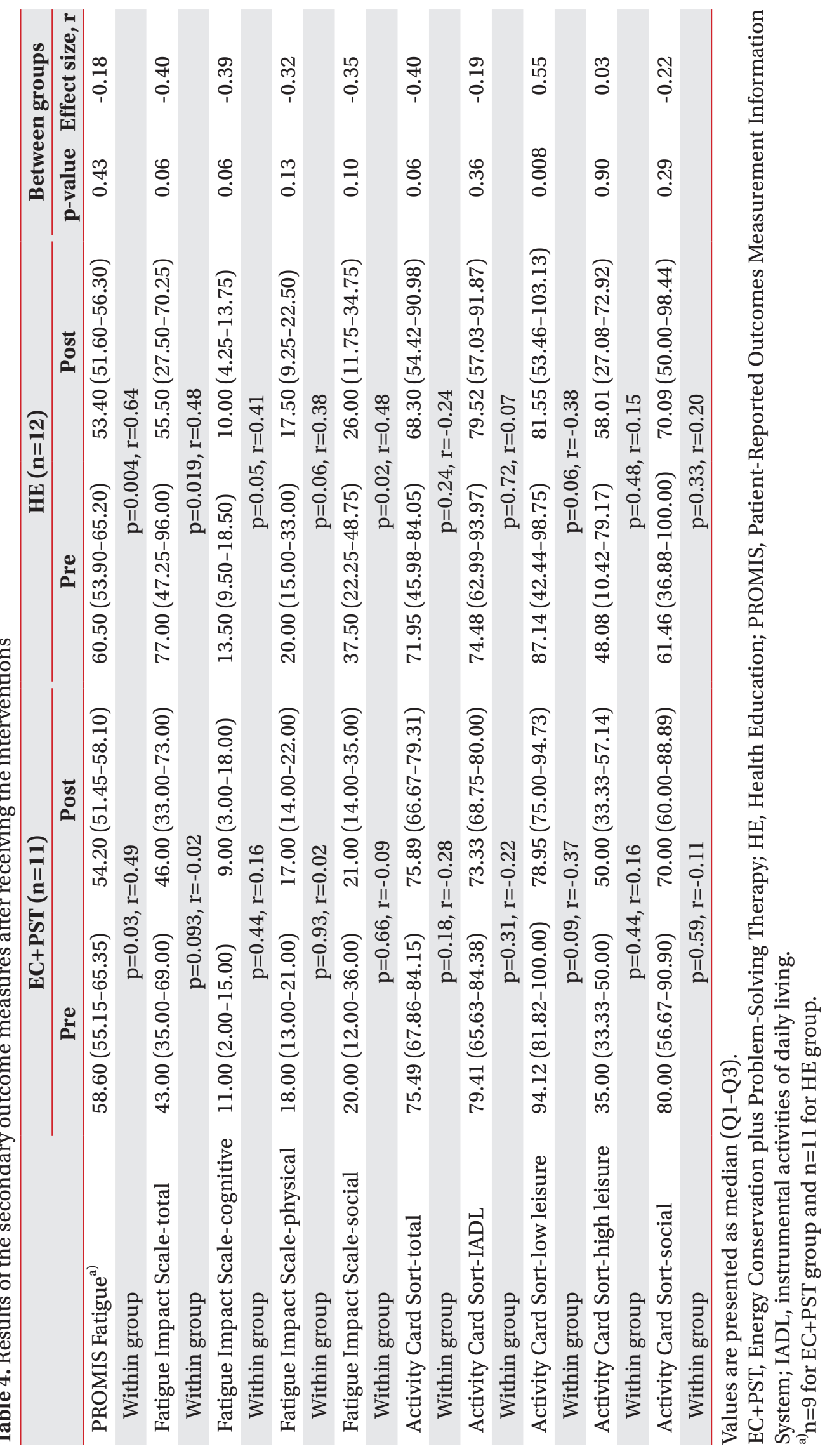


States, the Internet or telephone may be an acceptable intervention delivery method to increase the scalability of interventions in rural areas and to address disparities [36].

The PROMIS Fatigue 8a and Fatigue Impact Scale appropriately captured different aspects of fatigue in people with HF. Because the Fatigue Impact Scale instructs participants to reflect on their experience during the past 4 weeks and the PROMIS Fatigue 8a instructs them to focus on their experience during the past week, participants reported their experiences of fatigue impact and overall fatigue that occurred during the study participation. Participants were still learning new strategies during that time, especially those in the EC+PST group. Thus, longer follow-up may be more appropriate to measure the true effects of the interventions and long-term changes in fatigue.

Activity Card Sort may not be the best measure of activity participation for people diagnosed with HF far in the past. Participants were inconsistent in reporting the activities prior to their HF diagnosis that they had not performed. This may be related to the amount of time since they were first diagnosed with HF (6.7 and 8.8 years for the EC+PST group and the Health Education group, respectively). Therefore, Activity Card Sort may not be the best instrument to estimate the participation level of those whose illness/injuries occurred years prior to data collection. Another concern with Activity Card Sort is that the anchor point does not allow participants to report minor improvements in activities. Activity Card Sort Form B compares the current participation level to the level prior to the illness; therefore, participants may have been participating more after receiving the interventions but still less than what they did prior to illness. An assessment that measures the current participation level only, instead of comparing the current level to the specific past event, may be more appropriate for the current study objectives.

Both EC+PST and Health Education interventions were effective in reducing fatigue for people with $\mathrm{HF}$ and fatigue, although only the Health Education intervention was effective in reducing fatigue impact. These were consistent with previous findings. Both the EC+PST and Health Education interventions were shown to be effective in reducing fatigue in cardiac arrest survivors with fatigue, people with multiple sclerosis, or people with cancer-related fatigue $[17,37,38]$, although the formats of educational intervention vary. The EC+PST intervention was more effective in reducing participation level in low-physical demand leisure activities than the Health Education intervention. This may have occurred because participants in the EC+PST group were focusing on activities that required more energy, giving them less time for low-physical demand leisure activities. In fact, decreased participation in low-physical demand leisure activities was considered positive because these activities include sedentary activities such as playing computer games, reading books, playing cards, and watching television.

The major differences between the EC+PST intervention and Health Education intervention were the levels of interaction between the participant and the interventionist, engagement in problem solving, and action-required homework. In the EC+PST group, the participant and the interventionist actively interacted throughout the session to problem-solve the fatigue-related problems together. Also, participants were required to implement action plans in their daily activities during the study participation. Therefore, it is possible that this active engagement produced more fatigue for the participant. However, this active engagement may have not been reflected in Activity Card Sort because participants were still engaged in the limited number of activities compared to the wide range of activities in Activity Card Sort. Conversely, both the EC+PST and Health Education interventions share commonalities. Both the EC+PST and Health Education interventions provided detailed education on $\mathrm{HF}$ and fatigue; therefore, participants in both groups may have reported higher levels of fatigue at posttest than pretest because they had a greater understanding of what fatigue is and how it impacted their daily functioning. In addition, neither of the interventions take a remediating/restoring approach, but primarily focus on compensatory strategies. Therefore, the results may suggest that individuals with chronic HF may not benefit from compensatory strategies alone. Despite increasing the ability to participate in more activities using the compensatory strategies, they may continue to perceive that their fatigue is negatively affecting their daily lives. An addition of a remediating/restoring approach to compensatory strategies through a gradual increase in activity level, self-exercise, and diet modification by a multi-disciplinary team may be able to change their perception of the effect of fatigue. 
There are several limitations in our study. First, the assessors were not blinded to the study design and served as an interventionist in the study. However, all intervention outcome measures were self-reported and standardized, and assessors followed the standardized directions to ensure objectivity of the results. Therefore, the effect of this limitation on the results is minimal. Second, the number of sessions between the EC+PST intervention and Health Education intervention were not equivalent. More sessions were allocated to the EC+PST intervention because the dynamic interaction between the participant and the interventionist requires more time. The different number of sessions should be considered as the different characteristics of the interventions, rather than inequivalent dosage or contact. Furthermore, aiming to recruit a higher number of participants may have resulted in more comprehensive and accurate feasibility results. However, a long, 20-month recruitment period may have compensated this limitation. Lastly, participants' understanding on the principles of the EC+PST intervention was not examined. Although participants reported high understanding of the EC+PST Participant Workbook upon completion of their participation, we did not examine how well they understood the steps of EC+PST intervention and whether participants would be able to apply the steps to their problems on their own. Generalization is an important aspect of EC+PST intervention; therefore, measuring the mastery level of the EC+PST steps can be a useful measure to predict the future application ability of participants. In a future study, a double-blinded, blockand equal-randomized controlled trial with a sample size determined through a power analysis can be used to eliminate potential bias. In addition, to match the number of sessions between groups, sessions on the application of knowledge learned can be added to the Health Education intervention. Lastly, participants' understanding of the EC+PST intervention steps should be tested at the mid-point of the study to ensure generalization after study completion.

In conclusion, recruiting participants in Eastern North Carolina in the United States is feasible. Increasing the number of recruiting hospitals and obtaining multiple contact numbers may improve recruitment rate. Delivery of interventions through a tablet video-conferencing was feasible for people with HF and fatigue in the rural area, although it can be improved by adopting more reliable devices. Assessing participants with fatigue measures a few weeks later following completion of the interventions may result in more accurate results. Activity Card Sort may not be suitable to capture the current participation level for people with a long history of HF. Lastly, addition of a remediation approach may improve effectiveness of the EC+PST intervention.

\section{CONFLICT OF INTEREST}

No potential conflict of interest relevant to this article was reported.

\section{ACKNOWLEDGMENTS}

This work was supported by the 2016 Research and Creative Activity Award of East Carolina University, Greenville, NC, USA. The authors would like to thank Thomas Barnum, Brooke Biddle, Elizabeth Bishop, Jenna Laguarina, Jenny Chiariello, Nikki Faust, and Madison Wilcox for serving as assessors and interventionists, and the clinicians in Greenville, NC for referring participants.

\section{AUTHOR CONTRIBUTION}

Conceptualization: Kim YJ, Radloff JC. Methodology: Kim YJ, Radloff JC. Formal analysis: all authors. Funding acquisition: Kim YJ. Project administration: Kim YJ, Radloff JC. Visualization: all authors. Writing - original draft: Kim YJ. Writing - review and editing: all authors. Approval of final manuscript: all authors.

\section{REFERENCES}

1. Roger VL. Epidemiology of heart failure. Circ Res 2013;113:646-59.

2. Butrous H, Hummel SL. Heart failure in older adults. Can J Cardiol 2016;32:1140-7.

3. Tang WH, Francis GS. Clinical evaluation of heart failure. In: Mann DL, Felker GM, editors. Heart failure: a companion to Braunwald's heart disease. 3rd ed. Philadelphia: Elsevier; 2016. p. 421-37.

4. Smith OR, van den Broek KC, Renkens M, Denollet J. Comparison of fatigue levels in patients with stroke and patients with end-stage heart failure: application of the fatigue assessment scale. J Am Geriatr Soc 2008; 
56:1915-9.

5. Evangelista LS, Moser DK, Westlake C, Pike N, TerGalstanyan A, Dracup K. Correlates of fatigue in patients with heart failure. Prog Cardiovasc Nurs 2008; 23:12-7.

6. Falk K, Granger BB, Swedberg K, Ekman I. Breaking the vicious circle of fatigue in patients with chronic heart failure. Qual Health Res 2007;17:1020-7.

7. Hägglund L, Boman K, Lundman B. The experience of fatigue among elderly women with chronic heart failure. Eur J Cardiovasc Nurs 2008;7:290-5.

8. Dunlay SM, Roger VL. Understanding the epidemic of heart failure: past, present, and future. Curr Heart Fail Rep 2014;11:404-15.

9. Kluger BM, Krupp LB, Enoka RM. Fatigue and fatigability in neurologic illnesses: proposal for a unified taxonomy. Neurology 2013;80:409-16.

10. DeLuca J. Fatigue its definition, its study, and its future. In: DeLuca J, editor. Fatigue as a window to the brain. Cambridge: MIT Press; 2005. p. 319-326.

11. Lou JS. Physical and mental fatigue in Parkinson's disease: epidemiology, pathophysiology and treatment. Drugs Aging 2009;26:195-208.

12. Pozehl B, Duncan K, Hertzog M. The effects of exercise training on fatigue and dyspnea in heart failure. Eur J Cardiovasc Nurs 2008;7:127-32.

13. Corvera-Tindel T, Doering LV, Woo MA, Khan S, Dracup K. Effects of a home walking exercise program on functional status and symptoms in heart failure. Am Heart J 2004;147:339-46.

14. Oka RK, De Marco T, Haskell WL, Botvinick E, Dae MW, Bolen K, et al. Impact of a home-based walking and resistance training program on quality of life in patients with heart failure. Am J Cardiol 2000;85:3659.

15. Tsai BM. Feasibility and effectiveness of e-therapy on fatigue management in home-based older adults with congestive heart failure [dissertation]. Buffalo: University at Buffalo; 2008.

16. Mathiowetz VG, Finlayson ML, Matuska KM, Chen HY, Luo P. Randomized controlled trial of an energy conservation course for persons with multiple sclerosis. Mult Scler 2005;11:592-601.

17. Kim YJ, Rogers JC, Raina KD, Callaway CW, Rittenberger JC, Leibold ML, et al. An intervention for cardiac arrest survivors with chronic fatigue: a feasibility study with preliminary outcomes. Resuscitation 2016; 105:109-15.

18. Krupp LB, LaRocca NG, Muir-Nash J, Steinberg AD. The fatigue severity scale: application to patients with multiple sclerosis and systemic lupus erythematosus. Arch Neurol 1989;46:1121-3.

19. Woodford HJ, George J. Cognitive assessment in the elderly: a review of clinical methods. QJM 2007;100: 469-84.

20. Charlson ME, Pompei P, Ales KL, MacKenzie CR. A new method of classifying prognostic comorbidity in longitudinal studies: development and validation. J Chronic Dis 1987;40:373-83.

21. Lewinsohn PM, Seeley JR, Roberts RE, Allen NB. Center for Epidemiologic Studies Depression Scale (CESD) as a screening instrument for depression among community-residing older adults. Psychol Aging 1997; 12:277-87.

22. Holm B, Jacobsen S, Skjodt H, Klarlund M, Jensen T, Hetland ML, et al. Keitel Functional Test for patients with rheumatoid arthritis: translation, reliability, validity, and responsiveness. Phys Ther 2008;88:664-78.

23. Rosen LD, Whaling K, Carrier LM, Cheever NA, Rokkum J. The media and technology usage and attitudes scale: an empirical investigation. Comput Human Behav 2013;29:2501-11.

24. Lai JS, Cella D, Choi S, Junghaenel DU, Christodoulou C, Gershon R, et al. How item banks and their application can influence measurement practice in rehabilitation medicine: a PROMIS fatigue item bank example. Arch Phys Med Rehabil 2011;92(10 Suppl):S20-7.

25. Cella D, Lai JS, Jensen SE, Christodoulou C, Junghaenel DU, Reeve BB, et al. PROMIS fatigue item bank had clinical validity across diverse chronic conditions. J Clin Epidemiol 2016;73:128-34.

26. Frith J, Newton J. Fatigue impact scale. Occup Med (Lond) 2010;60:159.

27. Baum CM, Edwards D. ACS: activity card sort. 2nd ed. Bethesda: AOTA Press; 2008.

28. Cisco. Cisco WebEx Meetings [Internet]. [place unknown]: Cisco WebEx; c2019 [cited 2019 Nov 15]. Available from: http://www.webex.com.

29. Amazon. Fire Tablet with Alexa, 7" Display, 8 GB, Black - with special offers (previous generation - 5th) [Internet]. [place unknown]; Amazon.com; c2019 [cited 2019 Nov 15]. Available from: https://www. 
amazon.com/Amazon-Fire-7-Tablet-5th-Generation/ dp/B00TSUGXKE\#customerReviews.

30. Matthews MM. Cardiac and pulmonary disease. In: Pendleton HM, Schultz-Krohn W, editors. Pedretti's occupational therapy-e-book: practice skills for physical dysfunction. St. Louis: Elsevier Inc.; 2018. p. 111733.

31. Nezu AM, Nezu CM, D’Zurilla TJ. Problem-solving therapy: a treatment manual. New York: Springer; 2013.

32. Tickle-Degnen L. From the general to the specific: using meta-analytic reports in clinical decision making. Eval Health Prof 2001;24:308-26.

33. Powell LH, Calvin JE Jr, Richardson D, Janssen I, Mendes de Leon CF, Flynn KJ, et al. Self-management counseling in patients with heart failure: the heart failure adherence and retention randomized behavioral trial. JAMA 2010;304:1331-8.

34. Dracup K, Moser DK, Pelter MM, Nesbitt TS, Southard J, Paul SM, et al. Randomized, controlled trial to improve self-care in patients with heart failure living in rural areas. Circulation 2014;130:256-64.

35. Hageman PA, Pullen CH, Hertzog M, Pozehl B, Eisenhauer C, Boeckner LS. Web-based interventions alone or supplemented with peer-led support or professional email counseling for weight loss and weight maintenance in women from rural communities: results of a clinical trial. J Obes 2017;2017:1602627.

36. Bale B. Optimizing hypertension management in underserved rural populations. J Natl Med Assoc 2010; 102:10-7.

37. Wendebourg MJ, Heesen C, Finlayson M, Meyer B, Pottgen J, Kopke S. Patient education for people with multiple sclerosis-associated fatigue: a systematic review. PLoS One 2017;12:e0173025.

38. Bennett S, Pigott A, Beller EM, Haines T, Meredith P, Delaney C. Educational interventions for the management of cancer-related fatigue in adults. Cochrane Database Syst Rev 2016;11:CD008144. 